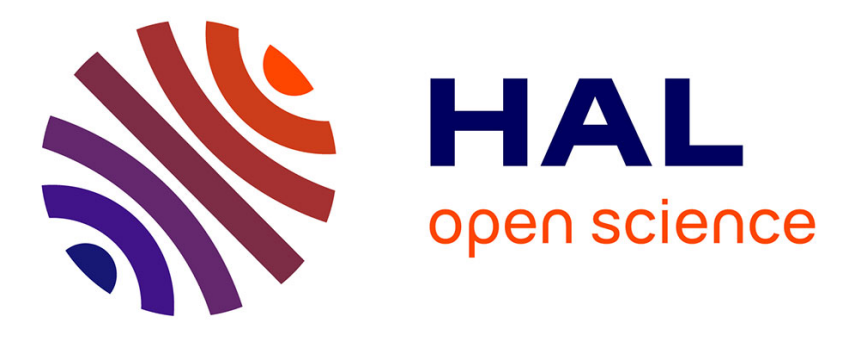

\title{
Postural control system influences intrinsic alerting state.
}

Julien Barra, Laurent Auclair, Agnès Charvillat, Manuel Vidal, Dominic

Pérennou

\section{- To cite this version:}

Julien Barra, Laurent Auclair, Agnès Charvillat, Manuel Vidal, Dominic Pérennou. Postural control system influences intrinsic alerting state.. Neuropsychology, 2015, 29, pp.226 - 234. 10.1037/neu0000174 . hal-01461221

\section{HAL Id: hal-01461221 https://hal-amu.archives-ouvertes.fr/hal-01461221}

Submitted on 17 Feb 2017

HAL is a multi-disciplinary open access archive for the deposit and dissemination of scientific research documents, whether they are published or not. The documents may come from teaching and research institutions in France or abroad, or from public or private research centers.
L'archive ouverte pluridisciplinaire HAL, est destinée au dépôt et à la diffusion de documents scientifiques de niveau recherche, publiés ou non, émanant des établissements d'enseignement et de recherche français ou étrangers, des laboratoires publics ou privés. 


\title{
Postural Control System Influences Intrinsic Alerting State
}

\author{
Julien Barra, Laurent Auclair, and Agnès Charvillat \\ Université Paris Descartes
}

\author{
Manuel Vidal \\ Aix-Marseille Université
}

\author{
Dominic Pérennou \\ Grenoble Université
}

\begin{abstract}
Objective: Numerous studies using dual-task paradigms (postural and cognitive) have shown that postural control requires cognitive resources. However, the influence of postural control on attention components has never been directly addressed. Method: Using the attention network test (ANT), which assesses specifically each of the 3 components of attention-alertness, orientation, and executive control - within a single paradigm, we investigated the effect of postural balance demand on these 3 components. Forty-two participants completed the ANT in 3 postural conditions: (a) supine, a very stable position; (b) sitting on a chair, an intermediate position; and (c) standing with feet lined up heel to toe, a very instable position known as the Romberg position. Results: Our results revealed that the difficulty of postural control does modulate alerting in such a way that it improves with the level of instability of the position. Regarding the orienting and executive control components of attention, performance was not different when participants were standing upright or seated, whereas in the supine position, performance dropped. Conclusions: The strong and specific interaction between postural control and the alerting system suggests that these mechanisms may share parts of the underlying neural circuits. We discuss the possible implication of the locus coeruleus, known to be involved in both postural balance and alerting. Also, our findings concerning orienting and executive control systems suggest that supine posture could have a specific effect on cognitive activities. These effects are discussed in terms of particularities resulting from the supine position.
\end{abstract}

Keywords: postural control, dual task, alertness, attention network test, supine position

Postural control is known to recruit attentional resources, which is best illustrated by interference with secondary tasks that are cognitively demanding (Kerr, Condon, \& McDonald, 1985). Diverting attention with such tasks depletes the resources available for balance control. In parallel, the difficulty of postural control has an impact on the performance of the secondary task. When the combination of both tasks becomes too difficult, which corresponds presumably to an attentional overload (Bourke, 1996; Pashler, 1994), effort on either one or the other of the tasks drops. If participants are required to maintain balance, performance in the cognitive task drops (Shumway-Cook, Woollacott, Kerns, \& Baldwin, 1997; Yardley et al., 2001; Chen et al., 1996). Conversely, if participants are required to think or speak, motor activity drops (Barra, Bray, Sahni, Golding, \& Gresty, 2006; Lundin-Olsson,

Julien Barra, Laboratoire Vision Action Cognition, Institut de Psychologie, Université Paris Descartes; Laurent Auclair, Institut de Psychologie, Université Paris Descartes; Agnès Charvillat, Laboratoire Mémoire et Cognition, Institut de Psychologie, Université Paris Descartes; Manuel Vidal, Institut de Neurosciences de la Timone, Aix-Marseille Université; Dominic Pérennou, Laboratoire de Psychologie et Neurocognition, Grenoble Université.

Correspondence concerning this article should be addressed to Julien Barra, Laboratoire Vision Action Cognition, Université Paris Descartes, 71 Avenue Edouard Vaillant, 92774 Boulogne-Billancourt Cedex France. E-mail: julien.barra@parisdescartes.fr

Nyberg, \& Gustafson, 1997). Accordingly, a decrease of performance on the cognitive side of a postural/cognitive dual-task paradigm has been consistently observed when postural control becomes harder (Andersson, Yardley, \& Luxon, 1998, 2002; Barra et al., 2006; Brauer, Woollacott, \& Shumway-Cook, 2001; Rapp, Krampe, \& Baltes, 2006; Riley, Baker, \& Schmit, 2003; Simoneau, Billot, Martin, Pérennou, \& Van Hoecke, 2008; Vuillerme, Nougier, \& Teasdale, 2000). Postural control difficulty has been found to be mainly modulated by reductions of the support base, as in feet-together standing (Mitra, 2004), standing with feet lined up heel to toe (Kerr et al., 1985), and balancing on a narrow beam (Barra et al., 2006).

The interaction of posture and cognition has been investigated with various types of cognitive tasks, ranging from simple backward counting to more complex tasks such as Stroop interferences (for a review, see Fraizer \& Mitra, 2008). The objective of previous studies was to evidence an interaction between posture and cognition, but the exact cognitive mechanisms or neural networks involved in the cognitive task were not really considered. The principal distinction between cognitive tasks resided in their verbal versus spatial nature. Because control of balance is a behavior involving spatial processing, the possibility that spatially and verbally related secondary cognitive tasks could have different effects was tested. Most studies found that both types of tasks interact with the balance behavior mechanisms (Bourke, 1996; Riley, Baker, Schmit, \& Weaver, 2005; Shumway-Cook et al., 1997; Swan, Otani, Loubert, Sheffert, \& Dunbar, 2004; Yardley et al., 
2001). The interaction between posture and cognition was, therefore, related to a general limitation of attention (Dault, Geurts, Mulder, \& Duysens, 2001; Redfern, Talkowski, Jennings, \& Furman, 2004; Siu, Chou, Mayr, van Donkelaar, \& Woollacott, 2009; Yardley et al., 2001) rather than a specific interference with spatial processing (Kerr et al., 1985; Maylor, Allison, \& Wing, 2001; Maylor \& Wing, 1996). Despite the very different nature and difficulty of the cognitive tasks tested, the conclusion that postural balance demands attentional resources was consistent across all these studies. However, the authors regarded attention as a general capacity or resource being involved in the various cognitive tasks, but they never addressed specifically the role of the different components of attention and their neural bases. For instance, Siu et al. (2009) concluded that attentional mechanisms contribute to balance constraints during gait using an auditory Stroop test as cognitive task. More recently, Ceyte et al. (2014) investigated the effect of a mental arithmetic task, consisting in backward counting by three or 13, on postural stabilization. According to the authors, the increase in body sway reported while performing such mental calculation was related to attempts to increase arousal (Ceyte et al., 2014). Nevertheless, viewed through the prism of modern cognitive psychology, the concept of attention used in these studies was very general, and attention was rarely specifically investigated in the cognitive part of the postural/cognitive dual-task paradigm. To our knowledge, only two studies have done so, but not with healthy participants. They measured the effect of body posture on levels of arousal and awareness in vegetative and minimally conscious patients (Elliott et al., 2005) and on a psychomotor vigilance task in sleep-deprived participants (Caldwell, Prazinko, \& Caldwell, 2003). In the present study, we aimed to investigate the influence of postural control on various components of attention in healthy participants using a cognitive task that addresses specifically attention. We adopted the framework proposed by Posner and Petersen (1990), which provides a strong theoretical framework for attention and its independent components together with a powerful behavioral paradigm that addresses each of these components with a unique and simple task. Further, precise data on the underlying neural basis of attention has been collected using this framework (Bush, Luu, \& Posner, 2000; Corbetta, Kincade, Ollinger, McAvoy, \& Shulman, 2000; Fossella et al., 2002; Yin et al., 2012).

The model of Posner and Petersen (1990) assumes that human attention is organized in independent brain circuits and neuromodulators that can be broken down into three networks implementing three components of attention (Fan, McCandliss, Sommer, Raz, \& Posner, 2002): alertness, orientation, and executive control. The role of the alerting network is to achieve and maintain an alert state. It is thought to depend on the right frontal and parietal lobes as well as the locus coeruleus (Fan et al., 2002; Posner \& Petersen, 1990). The orientation of (visual) attention corresponds to the selection of information from the sensory input, which involves the right parietal cortex (Corbetta et al., 2000; Fan et al., 2002). Finally, executive control is the level where decision making takes place and where error is monitored. It engages the anterior cingulate cortex and left prefrontal cortex (Bush et al., 2000; Fan et al., 2002).

Fan et al. (2002) proposed an attention network test (ANT) that assesses the three components of attention within a single experimental paradigm. The ANT requires participants to determine whether a central arrow points leftward or rightward. The arrow appears above or below a fixation cross and may be presented together with congruent, incongruent, or neutral flankers. The efficiency of each of the three attention networks can be measured with the influence of alerting cues, spatial cues, and flankers on the reaction times (RTs). The ANT appeared specifically adapted to directly investigate the possible influence of the postural control system on attention. The use of ANT as a cognitive task also allowed independent testing of the effect of posture on basic components of attention and disentanglement of the different processes that may account for effects observed with more complex cognitive tasks such as the Stroop task. Further, given that functional magnetic resonance imaging (fMRI) studies require participants to be supine during testing, it is technically impossible to directly investigate the neural correlates of postural balance in healthy participants. The posture/attention dual-task interference paradigm used in our experiment could be a solution to overcome this limitation, providing an indirect approach to assess whether the influence of postural control on the three different attentional components should be attributed to common neural substrates. Indeed, the dual-task interference has often been accounted for by the sharing of a limited set of specialized structures (Fraizer \& Mitra, 2008; Kahneman, 1973; Tombu \& Jolicœur, 2003; Wickens, 1980, 1984).

In our study, participants were required to complete the ANT (Fan et al., 2002) in three postural conditions involving very different balance difficulties: (a) a very stable position (supine participants), (b) an intermediate position (participants seated on a chair), and (c) a very instable position (participants standing with feet lined up heel to toe). We designed a graduation of postural difficulty, with extreme postures - including the supine positionthat have rarely been tested in a postural/cognitive dual-task paradigm. The supine posture requires very limited postural control, so cognitive performance in it should be maximal. We hypothesized that the more difficult the postural control was, the fewer resources could be allocated to the cognitive task, leading to a drop of performance in that task. We expected that the extreme graduation of postural difficulty would produce a clear graduation of performance on the cognitive task. As a consequence, postural control and cognitive processes would share some resources and, probably, underlying neural networks. Further, we distinguished the three components of attention to determine whether postural control could have a stronger impact on certain components than on the others. Some previous studies suggested that arousal may play a role in the posture/cognition interaction (Ceyte et al., 2014; Elliott et al., 2005), whereas others reported an interaction when using a Stroop task, known to involve executive functions (Barra et al., 2006; Kerr et al., 1985). We therefore hypothesized that that the alerting and executive control components would be gradually affected by the postural control level of difficulty.

\section{Method}

\section{Participants}

Forty-two healthy adults (mean age 52563 years; 24 women, 18 men) participated in the experiment. They had normal or corrected-to-normal vision (participants who wore glasses or contact lenses did so during the experiment), and none had any known neurological or oculomotor impairments. All participants were 
right-handed (according to the Edinburgh inventory; Oldfield, 1971) and gave their informed consent.

\section{Stimuli and Materials}

The stimuli were generated by the software E-Prime (Version 2.0; Psychology Software Tools, Sharpsburg, PA) and presented through a head-mounted display (HMD). The HMD (Z800 3DVisor; eMagin, Bellevue, WA) is a helmet-like device with two small color displays, one in front of each eye, covering $40^{\circ}$ of diagonal field of view with a resolution of 8003 600. This HMD was used to keep constant the distance between the eyes and the visual stimuli across experimental positions (supine, seated, and upright). A micro-electro-mechanical system (MEMS) gyroscope embedded in the HMD was used to record the medial-lateral angular velocity of the head. The visual target stimuli consisted of a horizontal black line, with arrowheads pointing leftward or rightward, against a gray background. This target was flanked on either side by two arrows pointing in the same direction (congruent condition) or in the opposite direction (incongruent condition) or by simple lines (neutral condition). Participants were asked to identify the direction of the central arrow by pressing the mouse's left or right button. Participants held the mouse in their right hand and used the thumb from the same hand to press the left or right button. A single arrow or line covered $0.55^{\circ}$ of visual angle, and the contours of adjacent arrows or lines were separated by $0.06^{\circ}$ of visual angle. The stimuli (one central arrow plus four flankers) covered a total of $3.08^{\circ}$ of visual angle. The targets could appear either $1.06^{\circ}$ above or $1.06^{\circ}$ below the fixation point

\section{Procedure}

To test the influence of postural behavior on the three components of attention, we asked participants to complete the ANT (Fan et al., 2002) in three different postures: (a) a very stable, low- demand postural control in which participants lay on their backs on a ridged platform (supine position); (b) an intermediate posture in which participants were seated on a ridged chair without seatback or armrests (seated position); and (c) a very instable, demanding posture in which participants stood upright with feet lined up heel t toe (upright position). These postures were chosen to minimize (supine position) and maximize (upright position) postural instability. Prior to the start of the experimental session, participants executed a 24-trial practice block in the seated position. During this training session, participants received feedback from the computer on their responses' speed and accuracy. The training session lasted approximately $2 \mathrm{~min}$.

According to the procedure of Fan et al. (2002), illustrated in Figure 1, four warning cue conditions were used: no cue (only the fixations cross appears), center cue (an asterisk appears at the location of fixation cross), double cue (an asterisk appears in the two possible target positions: up and down), and spatial cue (an asterisk appears in the future position of the target). Target location was always uncertain, except when the spatial cue was presented. Each trial began with a fixation period of random duration (400-1,600 ms). Then a warning cue was presented for $100 \mathrm{~ms}$ (in all cue conditions). There was a short fixation period of $400 \mathrm{~ms}$ after the warning cue and before the target and flankers appeared simultaneously. The target and flankers were presented until the participant responded, but for no longer than $1,700 \mathrm{~ms}$. After participants made a response, the target and flankers disappeared, and a fixation cross was presented for a variable duration that was based on the duration of the first fixation and on RT (3,500 ms minus the duration of the first fixation minus the RT). After this interval, the next trial began. Each trial lasted 4,000 ms. The fixation cross remained in the center of the screen during the whole trial.

The order of the three postural conditions was counterbalanced between participants and repeated three times for each participant 
so that there were three experimental blocks in each position. A break of $5 \mathrm{~min}$ was proposed between the different experimental blocks. Each experimental block consisted of 96 trials (4 cue conditions 32 target locations [up, down] 32 target directions [left, right] 33 flanker conditions [neutral, congruent, incongruent] 32 repetitions). The order of trial presentation was randomized. Participants were instructed to fixate at the centrally located fixation cross throughout a trial and to respond as quickly and accurately as possible. The RT and accuracy was recorded for each trial. Each experimental block took approximately $5 \mathrm{~min}$. Overall, the experiment lasted about an hour and a half.

The ANT (Fan et al., 2002) considers RT a dependent variable for each of the three attention networks, which allows computation of the effect of posture on each of the attentional components in terms of RT differences between pairs of task conditions. The alerting effect corresponds to the difference between the mean RT of the no cue conditions and the mean RT of the double cue conditions. The orienting effect corresponds to the difference between the mean RT of the center cue conditions and the mean RT of the spatial cue conditions. The executive control effect corresponds to the difference between the mean RT of incongruent flanking conditions and the mean RT of all congruent flanking conditions summed across cue types.

The variance of lateral head sway provided by the MEMS gyroscope was computed as the root mean square of the velocity.

\section{Analyses}

Analyses of variance (ANOVAs) were carried out on the RTs of correct responses with postural condition (supine, seated, upright) as a within-subject factor for each attention component (alerting, orienting, executive control). The eta-square was given as an indicator of effect size. To analyze the effects of posture on the alerting component, an ANOVA was carried out on the RTs of correct responses with position (supine, seated, upright) and cue conditions involved in the calculation of the alerting component (double cue condition, no cue conditions) as within-subject factors. Similarly, the effects in the orienting component were analyzed with an ANOVA carried out on the RTs of correct responses with position (supine, seated, upright) and the cue conditions implicated in the calculation of the orienting component (spatial cue condition, center cue condition) as within-subject factors. The orienting effect was analyzed with an ANOVA carried out on the RTs of correct responses with position (supine, seated, upright) and the type of target implicated in the calculation of executive control component (congruent flanking targets, incongruent flanking targets) as within-subject factors. For all analyses, post hoc tests were carried out using Tukey's honestly significant difference when needed. The statistical threshold for significance was set to .05.

\section{Results}

\section{Validation of the Experimental Design}

Accuracy (percentage of correct responses) was not different across postural conditions (supine: $97.6 \% 66.1 \%$; seated: $97.9 \% 6$ 4.4\%; and upright: $98.1 \% 64.5 \%$ [all $p \mathrm{~s} . .60]$ ), which allowed for computation and comparison of the contribution of each attentional component in the three postural conditions. Further, an
ANOVA carried out on the lateral velocity of the head (see Figure 2) with position (supine, seated, upright) as within-subject factor revealed an effect of the participant's position, $F(2,82) 5$ $89.05, p, .0001, \mathrm{~h}^{2} 5.68$. Post hoc tests confirmed that the supine position induced less head sway than the seated $(p$. .002) or upright $(p, .001)$ postures, whereas the upright posture induced more head instability than the seated position $(p, .0001)$. These results attest that the supine position was stable, the seated position was intermediate, and the upright position was instable.

\section{Alerting (No Cue2Double Cue)}

The ANOVA carried out on the RTs of correct responses with position (supine, seated, upright) as a within-subject factor for alerting revealed a main effect of position, $F(2,82) 5109.60, p$, $.0001, \mathrm{~h}^{2} 5$.73. Surprisingly, post hoc tests revealed that the alerting effect decreased when the posture became harder. Participants evidenced a larger alerting effect when they were supine than when they were seated $(p, .0001)$ or upright $(p, .0001)$. Further, in the upright position, which was the most demanding posture, participants showed a smaller alerting effect than in the seated position ( $p, .0001$; see Figure 3$)$.

The ANOVA carried out on the RTs of correct responses with position (supine, seated, upright) and the scores implicated in the calculation of a alerting effect (double-cue condition, no-cue condition) as within-subject factors allowed for decomposition of the alerting effect. Post hoc tests (see Figure 4) showed that the RTs observed in the no cue condition increased as postural difficulty decreased (supine vs. seated: $p, .0001$; supine vs. upright: $p$, .0001 ; seated vs. supine: $p, .0001$ ), whereas postural difficulty had no effect on the RTs observed in the double cue condition (supine vs. seated: $p 5$.98; supine vs. upright: $p 5$.80; seated vs. supine: $p 5$.99). The influence of postural control on alerting resulted exclusively from the RT decrease with postural difficulty in the no cue condition.

\section{Orienting (Center Cue2Spatial Cue)}

The ANOVA carried out on the RTs of correct responses with position (supine, seated, upright) as a within-subject factor for the

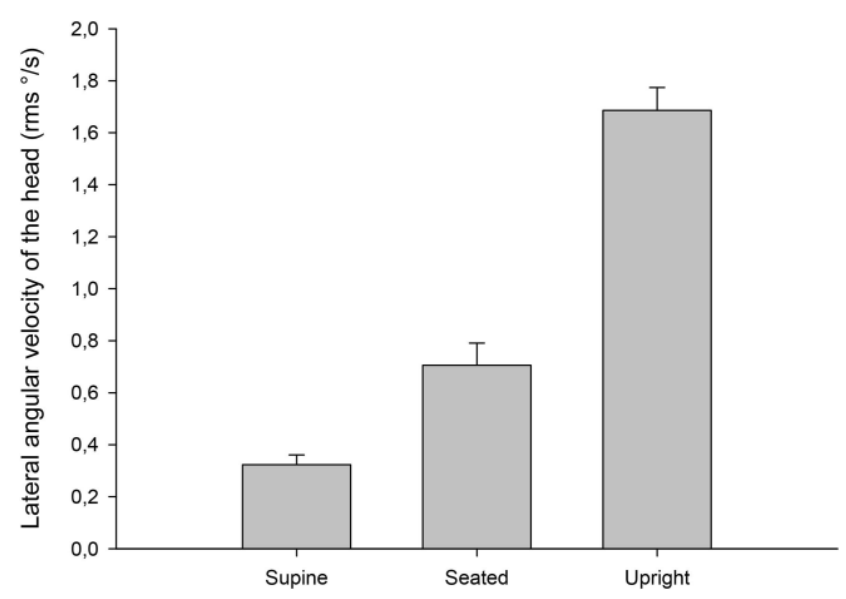

Figure 2. Mean sway variance for the three postural conditions. Error bars represent standard errors of the mean. rms 5 root mean square. 


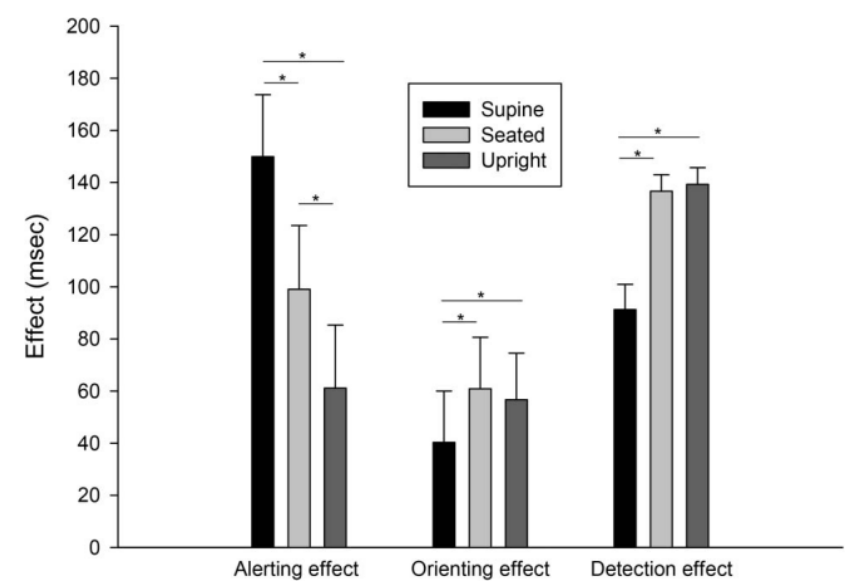

Figure 3. Mean effects (RT differences in milliseconds) of alerting (double cue-no cue), orienting (spatial cue-central cue), and executive control (incongruent flankers-congruent flankers) for the three postural conditions. Error bars represent standard errors of the mean.

orienting of visual attention revealed an effect of position, $F(2$, 82) $512.90, p, .0001, \mathrm{~h}^{2} 5.24$. Post hoc tests indicated that the orienting effect (see Figure 2) was lower in the supine position than in both the seated $(p, .0001)$ and the upright position $(p$, $.01)$. However, the orienting effects induced in seated and upright postures were not different ( $p 5$.10). The ANOVA carried out on the RTs of correct responses with position (supine, seated, upright) and the scores implicated in the calculation of the orienting effect (center cue condition, spatial cue condition) as within-subject factors allowed for disentanglement of the contribution of each components of the orienting effect. Post hoc tests (see Figure 5) showed that RTs observed in the supine position were longer than those in the seated $(p, .001)$ or upright $(p, .001)$ positions for the spatial cue conditions, whereas RTs were not different in the

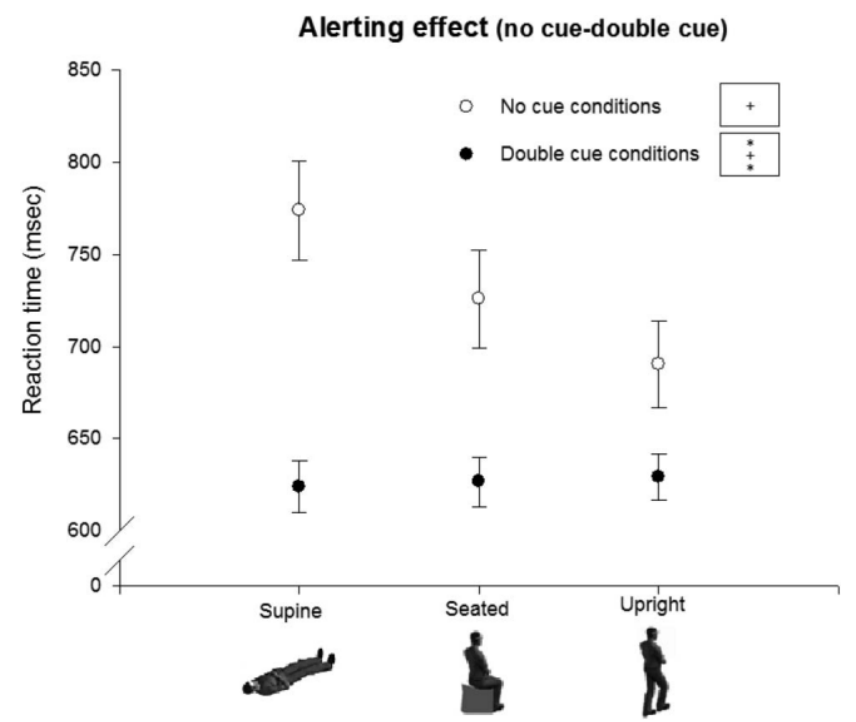

Figure 4. Mean reaction times used to compute the alerting effect for the three postural conditions. Error bars represent standard errors of the mean.

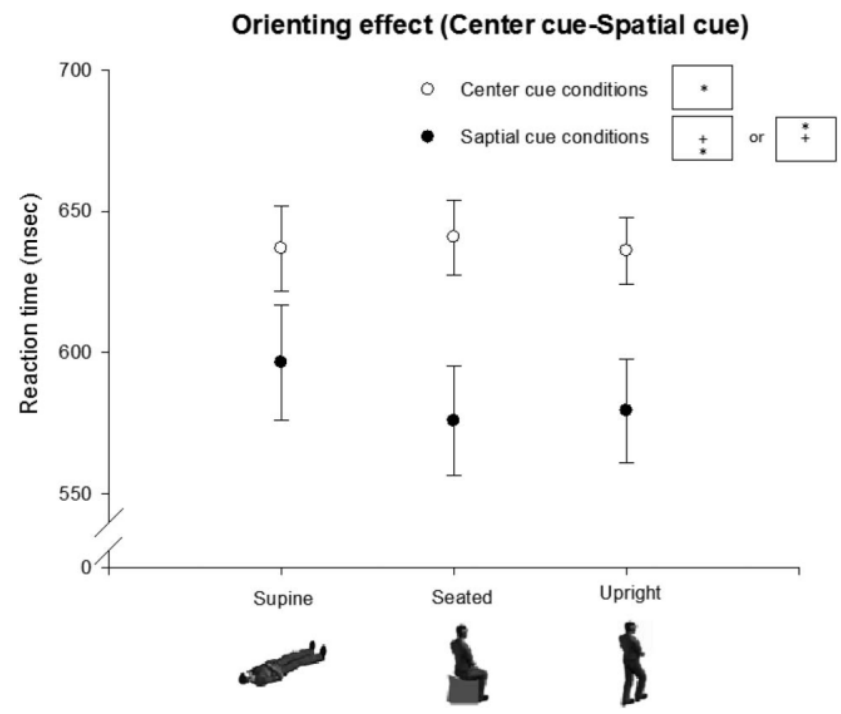

Figure 5. Reaction times used to compute the orienting effect for the three postural conditions. Error bars represent standard errors of the mean.

seated and upright positions ( $p 5$.95). Further, RTs in central cue conditions were not different across the three positions (supine vs. seated: $p 5.41$; supine vs. upright: $p 5.99$; seated vs. upright: $p 5$ $.30)$.

\section{Executive Control (Congruent Flanking 2 Incongruent Flanking)}

The analysis revealed a similar pattern of results for orienting and executive control effects. The ANOVA carried out on the RTs of correct responses with position (supine, seated, upright) as a within-subject factor for executive control revealed an effect of position, $F(2,82) 528.40, p, .0001, \mathrm{~h}^{2} 5.40$. Post hoc tests indicated that the executive control effect (see Figure 2) was lower in the supine position than in both the seated position $(p, .001)$ and the upright position $(p, .001)$. Nevertheless, the executive control effects induced in the seated and upright positions were not different ( $p 5$.90). The ANOVA carried out on the RTs of correct responses with position (supine, seated, upright) and the scores implicated in the calculation of executive control effect (congruent flanking conditions, incongruent flanking conditions) as withinsubject factors provided a decomposition of the executive control effect. Post hoc tests (see Figure 6) showed that RTs observed in the incongruent flanking conditions were comparable for the three postures (supine vs. seated: $p 5.10$; supine vs. upright: $p 5$.30; seated vs. upright: $p 5$.10). Nevertheless, in the congruent flanking conditions, RTs were longer in the supine position than they were in the seated $(p, .05)$ or upright positions $(p, .05)$, and no difference was detected between these ( $p 5$.94).

\section{Discussion}

To our knowledge, this study is the first in the literature to investigate a possible interplay between the allocation of resources for postural control and the three different components of attention: alerting, orienting, and executive control. It revealed that (a) 


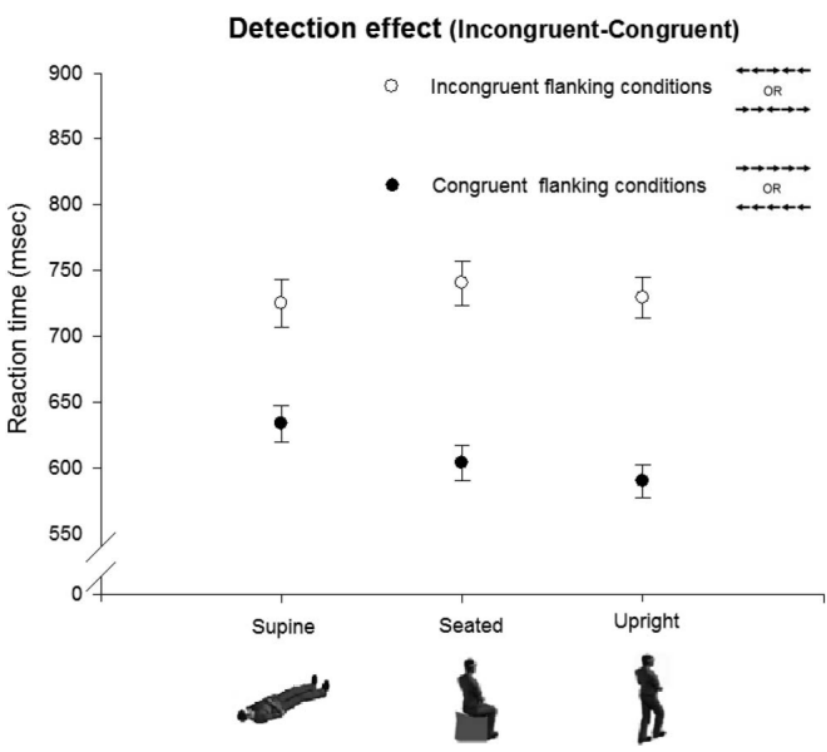

Figure 6. Mean reaction times used to compute the detecting effect for the three postural conditions. Error bars represent the standard errors of the mean.

the alerting network is the only attentional component to be gradually modulated by the difficulty of the postural task, (b) increasing balance difficulty improves the level of alerting, and (c) seated and upright positions induce a similar improvement of orienting and executive control components of attention relative to the supine position.

An improvement of attention performance in the most stable position (supine) was expected because this posture required very few attentional resources (Andersson, Hagman, Talianzadeh, Svedberg, \& Larsen, 2002; Andersson et al., 1998; Barra et al., 2006; Brauer et al., 2001; Rapp et al., 2006; Riley et al., 2003; Simoneau et al., 2008; Vuillerme et al., 2000). In fact, the main finding of this study revealed the reverse pattern as we showed that the more difficult the balance control became, the more participants became alert.

\section{Influence of Postural Control Difficulty on the Alerting Network}

The alerting effect that corresponds to the sensitivity to an alerting prime was computed as the subtraction of RT measured in alerting condition (double cue condition) and RT measured in a control condition (no cue condition). Neither of these conditions provided information about the location in which the target stimulus would appear. When no cue was presented, attention tended to remain diffused across the two potential target locations. The performance observed in this condition reflected the intrinsic state of alerting or arousal, with lower values indicating a high alerting level. In the double cue condition, attention also tended to remain diffused between the two potential target locations, while the participant was alerted to the imminent appearance of the target. Our experiment revealed that the alerting effect decreased gradually with increasing instability of body posture. Indeed, the alerting effect was lower in the upright position than in the seated position, but it was also lower in the seated position than in the supine position. The decomposition of the alerting effect indicated that the postural modulation did not influence how the alerting prime was processed, because RTs were similar in the three postural positions for the double cue condition. In contrast, in the control condition without an alerting priming (no cue condition), participants were faster when they stood upright than when they were seated and faster when they were seated than when they were supine. This pattern of results might be explained by the division of alertness into tonic and phasic alertness (Posner, 2008; Raz \& Buhle, 2006). Whereas tonic alertness refers to intrinsic and more long-term control of the arousal level independent of external warning cues, phasic alertness denotes brief adaptive increase in the arousal level pending an upcoming warning stimulus (Posner, 2008; Raz \& Buhle, 2006). We suggest that posture may have had an effect on tonic alertness or vigilance/arousal (mirrored by performance in the no cue condition) but no effect on phasic alertness (mirrored by performance in the double cue condition). This implies that the alerting effect found in the present study may have been attributable not to differing effectiveness of the alerting cue but to differences in baseline performance that might mirror differences in tonic alertness.

\section{Mechanisms Involved in the Influence of Postural Control on Alerting}

The sharing capacity theory (Fraizer \& Mitra, 2008; Kahneman, 1973; Tombu \& Jolicœur, 2003; Wickens, 1980, 1984) cannot account for our findings as this theory predicts a decrease in attention performance when postural difficulty increases. Nevertheless, it may be postulated that the more the neural networks involved in both posture and alerting are activated by postural task difficulty, the more the alerting state increases. The locus coeruleus is known to be involved in both alerting (Fan et al., 2002; Posner \& Petersen, 1990; McGregor \& Siegel, 2010) and balance control (Balaban, 2002) or regulation of muscular tone (Carter et al., 2010). Carter et al. (2010) found that levels of arousal and muscle tone can be regulated by varying the frequency of activation of locus coeruleus neurons and discovered a surprising loss of muscle tone triggered by high-frequency stimulation of this nucleus. Furthermore, locus coeruleus cells project rostrally, causing forebrain arousal (Aston-Jones \& Cohen, 2005). Therefore, the involvement of the locus coeruleus could increase when postural control becomes more difficult. This increased activation may also induce, in parallel, an increase in the alerting state. The influence of the locus coeruleus may be specific to alerting as the effects of orienting and executive control were not different in the seated and upright positions. Nevertheless, both orienting and executive control effects were shorter in the supine position than they were in the seated or upright positions, suggesting a specific effect of the supine position.

\section{Orienting and Executive Control Effects: A Specificity of the Supine position?}

The decrease of orienting and detecting effects in the supine position resulted from a reduction of the positive influence of spatial cue or congruence between the flankers and the target, respectively. In the upright and seated positions, the spatial prim- 
ing or congruence between the cue and the target induced a similar decrease in RT, suggesting that the difficulty of postural balance cannot explain the results observed in the supine position. In the upright position, it was very challenging for participants to maintain balance; however, performance in orienting and executive control was similar to that in the seated position, in which balance was not challenging at all. This absence of difference cannot stem from the paradigm being not sensitive enough to highlight it, as we could evidence differences in the alerting state between the same postural conditions. Altogether, these results indicate that participants were less prone to benefit from the cues in the supine position than they were in the seated or the upright position. The supine position may be a peculiar posture that has intrinsic effects on cognition.

In our experiment, the supine position had a specific effect on cognitive activities, but this effect cannot be attributed to the reduced postural balance demands (increased stability) for the orienting and executive control effects, because performance remained the same in both upright postures (seated on a chair and standing with feet lined up heel to toe). Previous studies have reported evidence for effects of postural changes on the level of arousal and awareness (Caldwell et al., 2003; Elliott et al., 2005; Funk, Finke, Müller, Preger, \& Kerkhoff, 2010; Harmon-Jones \& Peterson, 2009). Elliott et al. (2005) showed in vegetative and minimally conscious patients an arousal and awareness improvement when participants were in a standing position even though no change in blood pressure was observed. In this research, the clinical state of patients prevented postural instability or muscular activity from accounting for the effects observed on arousal. In line with these findings, our study revealed that postural instability and muscular activity may not be the key factors for the specific effect observed in the supine position for orienting and executive control. Some static components, inherent to the supine posture, may in fact be responsible for these effects. In the supine position, the body reference frame provided by somatosensory cues and the gravitational reference frame provided by the inertial cues are conflicting, which is not the case in upright positions (Barra, Chauvineau, Ohlmann, Gresty, \& Pérennou, 2007). Further, the supine posture swaps the role of the otolithic receptors (utricule and saccule) of the vestibular system, which achieve the detection of gravitational force. When the head is upright, the utricle responds to linear movements of the head in the horizontal plane, and the saccule responds to accelerations in the vertical plane (including gravity). In supine position, the utricle responds to accelerations of the head in the vertical plane, and the saccule responds to movements in the horizontal plane. Although the vestibular system is often considered a system for postural control and orientation, several studies have suggested that vestibular information contributes to numerous cognitive processes, including attention (Figliozzi, Guariglia, Silvetti, Siegler, \& Doricchi, 2005), memory (Smith, Geddes, Baek, Darlington, \& Zheng, 2010), orientation (Angelaki, Klier, \& Snyder, 2009), spatial representation (Ferrè, Longo, Fiori, \& Haggard, 2013), mental imagery (van Elk \& Blanke, 2014), attention risk perception (McKay et al., 2013), and even social cognition (Lopez, Falconer, \& Mast, 2013). These vestibular interactions with higher order spatial cognition could be based on the reference frame that the vestibular system provides for the brain.

\section{Implications of Supine Position for Interpretation of fMRI Results}

Interactions between posture and cognitive performance may have implications for the interpretation of fMRI studies, specifically when using tasks that involve the different components of attention. Indeed, it can be suggested that the brain network reported in the supine position during fMRI studies cannot be completely generalized to other postures, such as upright. These results may also explain the possible discrepancy between fMRI and electroencephalography (EEG) studies that has been reported (Harmon-Jones \& Peterson, 2009), which could stem from participants' postural differences (upright for EEG and supine for fMRI studies). Harmon-Jones and Peterson (2009) suggested that yet-tobe-discovered incidental physiological processes occurred as a result of the supine manipulation and affected the EEG data. Physiological processes such as cardiac rhythm, respiratory rate, and blood pressure regulation may vary in the supine position as compared with the upright position. These physiological modifications could, for example, have an impact on brain oxygenation, which in turn would affect cognitive processing. Further, vestibular (particularly from the otoliths), somatosensory, and proprioceptive information are dramatically modified by postural changes and have been proven to interfere with spatial cognition (Barra, Pérennou, Thilo, K., Gresty, \& Bronstein, 2012; Cheron et al., 2014). It can be speculated that these signal modifications could also play a role in the specific effects observed in the supine position. The exact nature of the effects observed in the supine position remains to be clarified.

\section{Conclusion}

To our knowledge, this study is the first to demonstrate that the level of difficulty in postural balance can modulate the intrinsic alerting state. We have clearly shown that the more postural control becomes difficult, the greater the intrinsic state of alerting. These results suggest that postural control and alerting may share neural circuits, the locus coeruleus being a potential candidate.

\section{References}

Andersson, G., Hagman, J., Talianzadeh, R., Svedberg, A., \& Larsen, H. C. (2002). Effect of cognitive load on postural control. Brain Research Bulletin, 58, 135-139. http://dx.doi.org/10.1016/S0361-9230(02)00770-0

Andersson, G., Yardley, L., \& Luxon, L. (1998). A dual-task study of interference between mental activity and control of balance. American Journal of Otolaryngology, 19, 632-637.

Angelaki, D. E., Klier, E. M., \& Snyder, L. H. (2009). A vestibular sensation: Probabilistic approaches to spatial perception. Neuron, 64, 448-461. http://dx.doi.org/10.1016/j.neuron.2009.11.010

Aston-Jones, G., \& Cohen, J. D. (2005). Adaptive gain and the role of the locus coeruleus-norepinephrine system in optimal performance. Journal of Comparative Neurology, 493, 99-110. http://dx.doi.org/10.1002/cne .20723

Balaban, C. D. (2002). Neural substrates linking balance control and anxiety. Physiology \& Behavior, 77, 469-475. http://dx.doi.org/ 10.1016/S0031-9384(02)00935-6

Barra, J., Bray, A., Sahni, V., Golding, J. F., \& Gresty, M. A. (2006). Increasing cognitive load with increasing balance challenge: Recipe for catastrophe. Experimental Brain Research, 174, 734-745. http://dx.doi .org/10.1007/s00221-006-0519-2 
Barra, J., Chauvineau, V., Ohlmann, T., Gresty, M., \& Pérennou, D. (2007). Perception of longitudinal body axis in patients with stroke: A pilot study. Journal of Neurology, Neurosurgery \& Psychiatry, 78, 43-48. http://dx.doi.org/10.1136/jnnp.2006.089961

Barra, J., Pérennou, D., Thilo, K. V., Gresty, M. A., \& Bronstein, A. M. (2012). The awareness of body orientation modulates the perception of visual vertical. Neuropsychologia, 50, 2492-2498. http://dx.doi.org/ 10.1016/j.neuropsychologia.2012.06.021

Bourke, P. A. (1996). A general factor involved in dual task performance decrement. Quarterly Journal of Experimental Psychology: Human Experimental Psychology, 49A, 525-545. http://dx.doi.org/10.1080/ 713755635

Brauer, S. G., Woollacott, M., \& Shumway-Cook, A. (2001). The interacting effects of cognitive demand and recovery of postural stability in balance-impaired elderly persons. Journals of Gerontology: Biological Sciences and Medical Sciences, 56A, M489-M496. http://dx.doi.org/ 10.1093/gerona/56.8.M489

Bush, G., Luu, P., \& Posner, M. I. (2000). Cognitive and emotional influences in anterior cingulate cortex. Trends in Cognitive Sciences, 4, 215-222. http://dx.doi.org/10.1016/S1364-6613(00)01483-2

Caldwell, J. A., Prazinko, B., \& Caldwell, J. L. (2003). Body posture affects electroencephalographic activity and psychomotor vigilance task performance in sleep-deprived subjects. Clinical Neurophysiology, 114, 23-31. http://dx.doi.org/10.1016/S1388-2457(02)00283-3

Carter, M. E., Yizhar, O., Chikahisa, S., Nguyen, H., Adamantidis, A., Nishino, S., . . . de Lecea, L. (2010). Tuning arousal with optogenetic modulation of locus coeruleus neurons. Nature Neuroscience, 13, 15261533. http://dx.doi.org/10.1038/nn.2682

Ceyte, H., Lion, A., Caudron, S., Kriem, B., Perrin, P. P., \& Gauchard, G. C. (2014). Does calculating impair postural stabilization allowed by visual cues? Experimental Brain Research, 232, 2221-2228. http://dx .doi.org/10.1007/s00221-014-3913-1

Chen, H. C., Schultz, A. B., Ashton-Miller, J. A., Giordani, B., Alexander, N. B., \& Guire, K. E. (1996). Stepping over obstacles: Dividing attention impairs performance of old more than young adults. Journals of Gerontology: Biological Sciences and Medical Sciences, 51A, M116-M122. http://dx.doi.org/10.1093/gerona/51A.3.M116

Cheron, G., Leroy, A., Palmero-Soler, E., De Saedeleer, C., Bengoetxea, A., Cebolla, A. M., . . McIntyre, J. (2014). Gravity influences top-down signals in visual processing. PLOS ONE, 9(1), e82371. http://dx.doi.org/ 10.1371/journal.pone.0082371

Corbetta, M., Kincade, J. M., Ollinger, J. M., McAvoy, M. P., \& Shulman, G. L. (2000). Voluntary orienting is dissociated from target detection in human posterior parietal cortex. Nature Neuroscience, 3, 292-297. http://dx.doi.org/10.1038/73009

Dault, M. C., Geurts, A. C., Mulder, T. W., \& Duysens, J. (2001). Postural control and cognitive task performance in healthy participants while balancing on different support-surface configurations. Gait \& Posture, 14, 248-255. http://dx.doi.org/10.1016/S0966-6362(01)00130-8

Elliott, L., Coleman, M., Shiel, A., Wilson, B. A., Badwan, D., Menon, D., \& Pickard, J. (2005). Effect of posture on levels of arousal and awareness in vegetative and minimally conscious state patients: A preliminary investigation. Journal of Neurology, Neurosurgery \& Psychiatry, 76, 298-299. http://dx.doi.org/10.1136/jnnp.2004.047357

Fan, J., McCandliss, B. D., Sommer, T., Raz, A., \& Posner, M. I. (2002). Testing the efficiency and independence of attentional networks. Journal of Cognitive Neuroscience, 14, 340-347. http://dx.doi.org/10.1162/ 089892902317361886

Ferrè, E. R., Longo, M. R., Fiori, F., \& Haggard, P. (2013). Vestibular modulation of spatial perception. Frontiers in Human Neuroscience, 7 , 660. http://dx.doi.org/10.3389/fnhum.2013.00660

Figliozzi, F., Guariglia, P., Silvetti, M., Siegler, I., \& Doricchi, F. (2005). Effects of vestibular rotatory accelerations on covert attentional orient- ing in vision and touch. Journal of Cognitive Neuroscience, 17, 1638 1651. http://dx.doi.org/10.1162/089892905774597272

Fossella, J., Sommer, T., Fan, J., Wu, Y., Swanson, J. M., Pfaff, D. W., \& Posner, M. I. (2002). Assessing the molecular genetics of attention networks. BMC Neuroscience, 3, 14. http://dx.doi.org/10.1186/14712202-3-14

Fraizer, E. V., \& Mitra, S. (2008). Methodological and interpretive issues in posture-cognition dual-tasking in upright stance. Gait \& Posture, 27, 271-279. http://dx.doi.org/10.1016/j.gaitpost.2007.04.002

Funk, J., Finke, K., Müller, H. J., Preger, R., \& Kerkhoff, G. (2010). Systematic biases in the tactile perception of the subjective vertical in patients with unilateral neglect and the influence of upright vs. supine posture. Neuropsychologia, 48, 298-308. http://dx.doi.org/10.1016/j .neuropsychologia.2009.09.018

Harmon-Jones, E., \& Peterson, C. K. (2009). Supine body position reduces neural response to anger evocation. Psychological Science, 20, 1209 1210. http://dx.doi.org/10.1111/j.1467-9280.2009.02416.x

Kahneman, D. (1973). Attention and effort. Englewood Cliffs, NJ: Prentice-Hall.

Kerr, B., Condon, S. M., \& McDonald, L. A. (1985). Cognitive spatial processing and the regulation of posture. Journal of Experimental Psychology: Human Perception and Performance, 11, 617-622. http://dx .doi.org/10.1037/0096-1523.11.5.617

Lopez, C., Falconer, C. J., \& Mast, F. W. (2013). Being moved by the self and others: Influence of empathy on self-motion perception. PLOS ONE, 8(1), e48293. http://dx.doi.org/10.1371/journal.pone.0048293

Lundin-Olsson, L., Nyberg, L., \& Gustafson, Y. (1997). "Stops walking when talking" as a predictor of falls in elderly people. The Lancet, 349 , 617. http://dx.doi.org/10.1016/S0140-6736(97)24009-2

Maylor, E. A., Allison, S., \& Wing, A. M. (2001). Effects of spatial and nonspatial cognitive activity on postural stability. British Journal of Psychology, 92, 319-338. http://dx.doi.org/10.1348/000712601162211

Maylor, E. A., \& Wing, A. M. (1996). Age differences in postural stability are increased by additional cognitive demands. Journals of Gerontology: Psychological Sciences and Social Sciences, 51B, P143-P154. http://dx .doi.org/10.1093/geronb/51B.3.P143

McGregor, R., \& Siegel, J. M. (2010). Illuminating the locus coeruleus: Control of posture and arousal. Nature Neuroscience, 13, 1448-1449. http://dx.doi.org/10.1038/nn1210-1448

McKay, R., Tamagni, C., Palla, A., Krummenacher, P., Hegemann, S. C., Straumann, D., \& Brugger, P. (2013). Vestibular stimulation attenuates unrealistic optimism. Cortex, 49, 2272-2275. http://dx.doi.org/10.1016/ j.cortex.2013.04.005

Mitra, S. (2004). Adaptive utilization of optical variables during postural and suprapostural dual-task performance: Comment on Stoffregen, Smart, Bardy, and Pagulayan (1999). Journal of Experimental Psychology: Human Perception and Performance, 30, 28-38.

Oldfield, R. C. (1971). The assessment and analysis of handedness: The Edinburgh Inventory. Neuropsychologia, 9, 97-113.

Pashler, H. (1994). Dual-task interference in simple tasks: Data and theory. Psychological Bulletin, 116, 220-244. http://dx.doi.org/10.1037/00332909.116.2.220

Posner, M. I. (2008). Measuring alertness. In D. W. Pfaff \& B. L. Kieffer (Eds.), Molecular and biophysical mechanisms of arousal, alertness, and attention: Annals of the New York Academy of Sciences (Vol. 1129, pp. 193-199). New York: Wiley. http://dx.doi.org/10.1196/annals.1417 .011

Posner, M. I., \& Petersen, S. E. (1990). The attention system of the human brain. Annual Review of Neuroscience, 13, 25-42. http://dx.doi.org/ 10.1146/annurev.ne.13.030190.000325

Rapp, M. A., Krampe, R. T., \& Baltes, P. B. (2006). Adaptive task prioritization in aging: Selective resource allocation to postural control is preserved in Alzheimer disease. American Journal of Geriatric Psychi- 
atry, 14, 52-61. http://dx.doi.org/10.1097/01.JGP.0000192490 $.43179 . \mathrm{e} 7$

Raz, A., \& Buhle, J. (2006). Typologies of attentional networks. Nature Reviews Neuroscience, 7, 367-379. http://dx.doi.org/10.1038/nrn1903

Redfern, M. S., Talkowski, M. E., Jennings, J. R., \& Furman, J. M. (2004). Cognitive influences in postural control of patients with unilateral vestibular loss. Gait \& Posture, 19, 105-114. http://dx.doi.org/10.1016/ S0966-6362(03)00032-8

Riley, M. A., Baker, A. A., \& Schmit, J. M. (2003). Inverse relation between postural variability and difficulty of a concurrent short-term memory task. Brain Research Bulletin, 62, 191-195. http://dx.doi.org/ 10.1016/j.brainresbull.2003.09.012

Riley, M. A., Baker, A. A., Schmit, J. M., \& Weaver, E. (2005). Effects of visual and auditory short-term memory tasks on the spatiotemporal dynamics and variability of postural sway. Journal of Motor Behavior, 37, 311-324. http://dx.doi.org/10.3200/JMBR.37.4.311-324

Shumway-Cook, A., Woollacott, M., Kerns, K. A., \& Baldwin, M. (1997). The effects of two types of cognitive tasks on postural stability in older adults with and without a history of falls. Journals of Gerontology: Biological Sciences and Medical Sciences, 52A, M232-M240. http://dx .doi.org/10.1093/gerona/52A.4.M232

Simoneau, E. M., Billot, M., Martin, A., Pérennou, D., \& Van Hoecke, J. (2008). Difficult memory task during postural tasks of various difficulties in young and older people: A pilot study. Clinical Neurophysiology, 119, 1158-1165. http://dx.doi.org/10.1016/j.clinph.2008.01.020

Siu, K. C., Chou, L. S., Mayr, U., van Donkelaar, P., \& Woollacott, M. H. (2009). Attentional mechanisms contributing to balance constraints during gait: The effects of balance impairments. Brain Research, 1248, 59-67. http://dx.doi.org/10.1016/j.brainres.2008.10.078

Smith, P. F., Geddes, L. H., Baek, J. H., Darlington, C. L., \& Zheng, Y. (2010). Modulation of memory by vestibular lesions and galvanic vestibular stimulation. Frontiers in Neurology, 1, 141. http://dx.doi.org/ 10.3389/fneur.2010.00141
Swan, L., Otani, H., Loubert, P. V., Sheffert, S. M., \& Dunbar, G. L. (2004). Improving balance by performing a secondary cognitive task. British Journal of Psychology, 95, 31-40. http://dx.doi.org/10.1348/ 000712604322779442

Tombu, M., \& Jolicœur, P. (2003). A central capacity sharing model of dual-task performance. Journal of Experimental Psychology: Human Perception and Performance, 29, 3-18. http://dx.doi.org/10.1037/00961523.29.1.3

van Elk, M., \& Blanke, O. (2014). Imagined own-body transformations during passive self-motion. Psychological Research, 78, 18-27. http:// dx.doi.org/10.1007/s00426-013-0486-8

Vuillerme, N., Nougier, V., \& Teasdale, N. (2000). Effects of a reaction time task on postural control in humans. Neuroscience Letters, 291, 77-80. http://dx.doi.org/10.1016/S0304-3940(00)01374-4

Wickens, C. (1980). The structure of attentional resources. In R. S. Nickerson (Ed.), Attention and performance VIII (pp. 239-257). Hillsdale, NJ: Erlbaum.

Wickens, C. (1984). Processing resources in attention. In R. Parasuraman \& D. R. Davies (Eds.), Varieties of attention (pp. 221-229). New York: Academic Press.

Yardley, L., Gardner, M., Bronstein, A., Davies, R., Buckwell, D., \& Luxon, L. (2001). Interference between postural control and mental task performance in patients with vestibular disorder and healthy controls. Journal of Neurology, Neurosurgery \& Psychiatry, 71, 48-52. http://dx .doi.org/10.1136/jnnp.71.1.48

Yin, X., Zhao, L., Xu, J., Evans, A. C., Fan, L., Ge, H., . . Liu, S. (2012). Anatomical substrates of the alerting, orienting and executive control components of attention: Focus on the posterior parietal lobe. PLoS ONE, 7 (11), e50590. http://dx.doi.org/10.1371/journal.pone.0050590 